
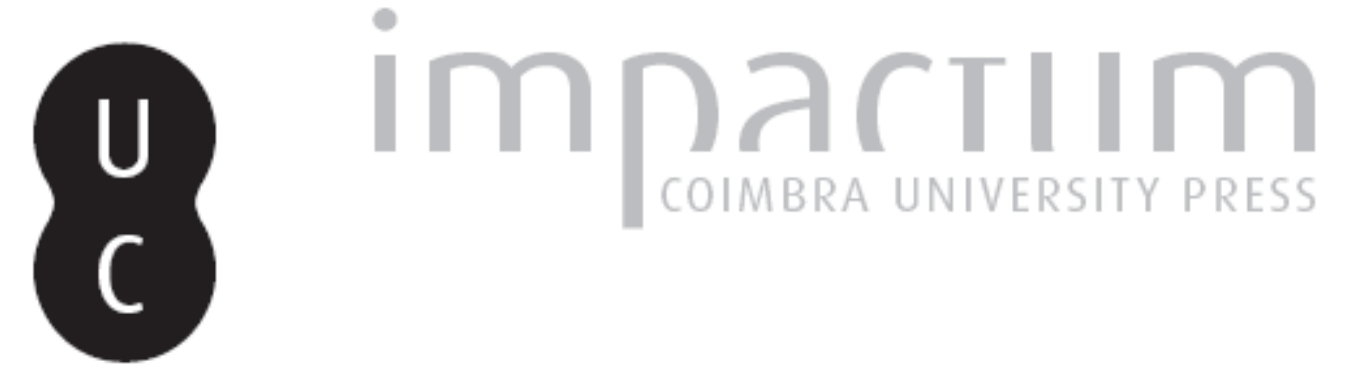

\title{
A pedagogia do Latim no século XVI: o comentário de Aires Barbosa à história apostolica de Arátor
}

Autor(es): $\quad$ Manso, José Henrique Rodrigues

Publicado por: Associação Portuguesa de Estudos Clássicos; Instituto de Estudos

URL

persistente:

DOI: $\quad$ DOI:http://dx.doi.org/10.14195/0872-2110_52_13

Accessed : $\quad$ 26-Apr-2023 15:26:51

A navegação consulta e descarregamento dos títulos inseridos nas Bibliotecas Digitais UC Digitalis, UC Pombalina e UC Impactum, pressupõem a aceitação plena e sem reservas dos Termos e Condições de Uso destas Bibliotecas Digitais, disponíveis em https://digitalis.uc.pt/pt-pt/termos.

Conforme exposto nos referidos Termos e Condições de Uso, o descarregamento de títulos de acesso restrito requer uma licença válida de autorização devendo o utilizador aceder ao(s) documento(s) a partir de um endereço de IP da instituição detentora da supramencionada licença.

Ao utilizador é apenas permitido o descarregamento para uso pessoal, pelo que o emprego do(s) título(s) descarregado(s) para outro fim, designadamente comercial, carece de autorização do respetivo autor ou editor da obra.

Na medida em que todas as obras da UC Digitalis se encontram protegidas pelo Código do Direito de Autor e Direitos Conexos e demais legislação aplicável, toda a cópia, parcial ou total, deste documento, nos casos em que é legalmente admitida, deverá conter ou fazer-se acompanhar por este aviso. 


\section{Boletim de}

\section{Estudos Clássicos}

Associação Portuguesa de Estudos Clássicos Instituto de Estudos Clássicos

Coimbra

Dezembro de 2009 


\section{A Pedagogia do latim no SÉculo XVI: O Comentário DE AIRES BARBosa À Historia Apostolica de ARÁtor}

O minucioso comentário à Historia apostolica de Arátor que o aveirense Aires Barbosa publicou em 1516, em Salamanca, além da sua importância em múltiplas áreas do saber, tem particular interesse para a história da metodologia do latim, e é este aspecto que pretendemos patentear neste artigo. Sendo o Boletim uma revista de prestígio que, há vários anos, tem vindo a fornecer aos docentes instrumentos didácticos preciosos no ensino das línguas clássicas, não será, pois, despiciendo incluir nas suas páginas a perspectiva pedagógica do latim de Aires Barbosa, nos alvores do século XVI.

Apesar de ter publicado toda a sua obra na língua do Lácio, Aires Barbosa ficou conhecido pelo epíteto de Mestre Grego; bem merecido, aliás. Tendo ininterruptamente regido a cátedra de Grego ao longo dos quase trinta anos que leccionou na Universidade de Salamanca, a partir de 1495 e até à sua aposentação em 1524, foi Barbosa o primeiro a dirigir esta disciplina ao nível universitário na Península Ibérica. E o prestígio que Barbosa imprimiu ao ensino da língua helénica não é só atestado pelo epíteto acima referido. São os colegas, os discentes e, posteriormente, os críticos que comprovam a excelência do ensino do grego que, aliado à não menos afamada docência do latim, fazem de Aires Barbosa um dos mais prestigiados pedagogos da instituição salmantina no primeiro quartel de Quinhentos. André de Resende, por exemplo, no Elogio a Erasmo, destaca o facto de Barbosa ter sabido passar o esplendor da cultura helénica para a língua latina:

O venerando Aires [Barbosa], por seus grandes méritos honra insigne da Espanha, a quem os estudos superiores devem quanto de Palas ali têm, pois ele foi o primeiro que ensinou os Iberos a dispor palavras gregas com a harmonia de Hipocrene: em boa verdade, quanta riqueza agora têm os ítalos reinos e quanta a Grécia outrora teve, ele as importou para a pátria e para 
os seus e, por fim, defendendo-os do solecismo gaulês, lhes concedeu tornarem-se quirites na linguagem ${ }^{1}$.

E se insistimos nesta questão, é porque havia a ideia de que, não só ao nível da cultura como também da própria língua, o grego era sentido como a fonte da língua latina ${ }^{2}$. Por outro lado, a língua helénica funcionava para os humanistas como altera uox, isto é, como meio de acesso a outras fontes, e o perfeito domínio do grego era prova de grande sapiência, até pela raridade dos especialistas. Com efeito, nos inícios de Quinhentos, em Salamanca, apesar de termos por cenário o movimento renascentista, que, na sua primeira acepção, visava fazer "renascer" em todo o seu esplendor as línguas clássicas, a verdade é que o conhecimento do grego era muito ténue e impreciso e, fazendo fé nas palavras do nosso humanista, também o latim não andava muito bem tratado:

Se alguém, de facto, tentar dizer uma palavra latina, / riem dele como de um louco e chamam-no gramático. / E então ouvir sons gregos no meio deles é como se fosse um fenómeno, / isso é obra de maior espanto que mula prenhe. ${ }^{3}$

Barbosa pugnou pela restauração das línguas e do saber greco-latinos, mas também, como humanista que era, pela primazia das letras humanas na cultura, não significando tal atitude um desacordo com a sociedade

1 Vd. André de Resende, Elogio de Erasmo (Erasmi encomium), estabelecimento do texto e tradução de Walter Medeiros e José Pereira da Costa, Lisboa, Instituto de Alta Cultura, 1961, p. 25 (v. 238-245). André de Resende chegou a Salamanca por volta de 1517 para aprender grego com Aires Barbosa. Ficaria para sempre ligado ao mestre pelos vínculos de uma amizade e admiração profundas.

2 No início do século XVI, havia a concepção de que o grego, língua fundamental da Patrística, era imprescindível para uma boa formação teológica, tanto mais que ela era vista como sendo a base do latim. O cardeal Cisneros, que, na fundação do Colégio de S. Ildefonso em Alcalá de Henares, teve sobretudo em mente a formação de eclesiásticos, justifica, nas Constituições que lhe autorgou em 1510, a criação da cátedra de Grego nestes termos: «quoniam lingua Graeca fons est et origo Latinae linguae et aliarum scientiarum». Vd. José López Rueda, Helenistas españoles del siglo XVI, Madrid, Instituto Antonio de Nebrija, 1973, p. 18.

3 Vd. epigrama Ad iuuenes studiosos, v. 7-10. Tradução de Sebastião Pinho, Humanismo em Portugal. Estudos, I, Lisboa, IN-CM, 2006, p. 108. 
eclesiástica ou com as estruturas espirituais do seu tempo. No epigrama De officio grammatici, o humanista esclarece que o título de gramático, tal como era entendido pelos antigos, não podia ser dado a qualquer um, e menos ainda no seu tempo:

Nos nossos dias, só um floresceu: Élio António de Nebrija, / digno de todo o louvor pela renovação que operou nas letras. ${ }^{4}$

Chegamos aqui a um ponto importante: a renovação do ensino em Salamanca através dos ventos da renovação trazidos de Itália. Barbosa foi aluno, colega e amigo do grande humanista António de Nebrija e ambos tiveram uma formação académica semelhante (ainda que em tempos diversos), frequentando primeiro a Universidade de Salamanca e, depois, as universidades italianas, onde hauriram o saber de grandes mestres, como Lorenzo Valla ou Ângelo Policiano. Os dois regressariam a Salamanca, tornando-se insignes professores daquela instituição. Ora, como sublinha Veríssimo Serrão, Barbosa foi o continuador e, nalguns aspectos, superou mesmo o mestre, porque, como já foi atrás referido, o português possuía um sólido conhecimento do grego ${ }^{5}$.

Tanto Barbosa como Nebrija reinvindicaram para o gramático autoridade sobre a interpretação de todo o tipo de textos literários, fossem eles sagrados ou profanos. Nebrija comentou Pérsio e Virgílio, mas também Prudêncio e Sedúlio, sobre os quais produziu edições comentadas, no âmbito da sua actividade docente. Assim, editou o Opus Paschale, de Sedúlio, em

4 «Tempore sed nostro florens Antonius unus / laude uir insigni saecula cuncta nouat». Seguimos a tradução de José Sebastião Dias (A política cultural da época de D. João III, I, Coimbra, Instituto de Estudos Filosóficos da Universidade de Coimbra, 1969, p. 218). O epigrama encontra-se nas Introductiones Latinae, de Nebrija, publicadas em 1495, e foi posteriormente reeditado por Barbosa na colecção de 1536 que juntou à Antimoria, onde, curiosamente, estão omitidos estes versos.

5 Cf. Joaquim Veríssimo Serrão, Portugueses no estudo de Salamanca, I, (1250-1550), Lisboa, s/e, 1969, p. 151: «Evocar o nome de Aires Barbosa implica o estudo do renascimento das línguas clássicas na Universidade e o seu papel de herdeiro espiritual de Nebrija»; e p. 107: «Mas a semente lançada por Nebrija pôde frutificar graças ao labor de Aires Barbosa. À formação greco-latina de que o mestre dera testemunho, o humanista lusitano juntava uma autoridade superior em matéria de erudição helénica» 
1508, obra que teve a fortuna de ser reeditada amiúde nas duas décadas seguintes. Em 1512, o humanista espanhol fez sair a Psicomachia, de Prudêncio. Seguindo-lhe o exemplo, Barbosa aventurou-se pelos versos de outro épico cristão, Arátor, explicando minuciosamente a Historia apostolica aos seus alunos, em 1513, e tendo publicado o comentário três anos mais tarde $^{6}$. Nesta perspectiva, ganham novo significado as considerações do humanista português no prefácio ao primeiro livro do comentário, quando, ao afirmar a excelência e a dificuldade dos versos de Arátor, menoriza os obstáculos com que alguns comentadores se depararam na abordagem dos outros épicos:

$\mathrm{Na}$ verdade, embora eles naveguem facilmente pelos poemas dos restantes vates cristãos, como se fosse através de certos lagos, e expliquem aos seus discípulos os poemas de Prudêncio, de Sedúlio, de Juvenco, como se velejassem num porto, temem aproximar-se deste [Arátor], ou, se se aproximam, abordam apenas os lugares próximos e as margens da beira da praia, temendo o alto mar, e em parte alguma se afastando para muito longe da terra ${ }^{7}$.

A Historia apostolica, poema épico apresentado pelo próprio Arátor ao papa Vigílio no ano de 544, é constituída por mais de dois milhares de hexâmetros dactílicos que retratam a gesta apostólica de Pedro (livro 1) e a de Paulo (livro 2), seguindo o texto lucano dos Actos dos apóstolos. Um dos primeiros aspectos que convém salientar, para quem se aventura no estudo do poema, é que o latim desta obra é extremamente rebuscado, com construções sintácticas muito engenhosas e inusitadas e um vocabulário que oscila entre a

6 Esta informação é-nos dada pelo humanista na abertura do comentário: «Todos os dias me pedis, caríssimos ouvintes, ou antes, implorais com todas as preces e suplicais que publique os comentários que eu mesmo compus numa obra desorganizada e que, durante as minhas ocupações, nesse tempo, não me foi possível rever, quando eu comentava publicamente, há um triénio, o poeta Arátor, que escreveu em verso os Actos dos apóstolos». Vd. Aires Barbosa, Aratoris cardinalis Historia apostolica cum commentariis Arii Barbosae Lusitani, Salmanticae, in aedibus Ioannis de Porris, 1516, fl. ii, l. 1-3, tradução nossa.

${ }^{7}$ Vd. ibidem, fl. ii, l. 6-9, tradução nossa. 
imitação dos épicos latinos e o latim mais tardio e medieval ${ }^{8}$. Ora, dessa dificuldade nos dá conta Barbosa que, mesmo assim, não virou costas à responsabilidade, antes se terá sentido desafiado pelos versos de Arátor, um poeta de ampla divulgação durante toda a Idade Média. O resultado foi a publicação do primeiro estudo sobre Historia apostolica, que, tanto quanto julgamos, é também o mais completo sobre Arátor, na medida em que abarca toda a obra. Não obstante, o comentário barbosiano não tem granjeado a atenção merecida, já que só marginalmente os estudiosos de Arátor lhe fazem curtas referências.

O valor do comentário de Aires Barbosa para a história da pedagogia do Latim pode medir-se por isto: ele funciona como uma espécie de máquina do tempo que nos permite recuar quinhentos anos e ver como funcionava uma aula de Latim numa universidade europeia. Mais ainda, permite-nos ver como novos métodos de abordagem da literatura latina foram implementados por essa altura em Salamanca e como eles originaram divisões e atritos entre os mestres salmantinos. Conseguimos visualizar como era feita a abordagem a um texto latino, neste caso, a epopeia bíblica de Arátor. Não havia lugar à tradução, pois toda a aula era em latim. O professor dedicava todo o tempo da lição à compreensão do texto, através de inúmeros esclarecimentos sintácticos e semânticos mais adstritos à Historia apostolica em si.

De facto, devemos ter em consideração que se trata de uma obra pedagógica, cujos principais destinatários são, em vez dos lectores, os auditores, isto é, os alunos que escutaram o humanista na interpretação da obra de Arátor ${ }^{9}$. Por conseguinte, o esclarecimento da difícil sintaxe do texto

8 Cf. Jacques Fontaine, Naissance de la poésie dans l'occident chrétien. Esquisse d'une histoire de la poésie chrétienne du $I I I^{e}$ au VI $I^{e}$ siècle, Paris, Études Augustiniennes, 1981, p. 263: «Au terme d'un siècle, on est ici déjà loin, même à Rome, de la maîtrise et de la limpidité soigneusement décantée d’un Sedulius. L'obscurité naît souvent, dans ses vers, d'une rencontre dissonante entre une recherche extrême et un état de langue qui ne possède plus la souplesse nécessaire pour se plier à la réussite de ces tours».

9 Barbosa faz preceder o comentário a cada um dos livros de Arátor de dois exórdios, encabeçados pela dedicatória «Prefácio do português Aires Barbosa dirigido aos jovens estudiosos das belas letras», que mais não são do que os seus próprios discípulos, invocados frequentemente nos dois textos com recurso ao superlativo: «auditores amantissimi», «auditores suauissimi» e «auditores iucundissimi». Nestes textos, Barbosa apresenta as motivações e as dificuldades do comentário, assim como 
aratoriano e do significado vocabular impunha-se como o primeiro passo a dar, para depois se poderem estabelecer relações cada vez mais alargadas até se chegar ao conteúdo e à mensagem do texto. Daqui resulta, muitas vezes, a monotonia do comentário, repetindo exaustivamente as expressões id est e scilicet, que introduzem a explicação da ordem ou do significado de um vocábulo ou expressão. Vejamos um caso exemplificativo de esclarecimento semântico, num passo em que o humanista comenta os versos 6-8 do segundo livro da Historia apostolica:

Quae, scilicet, Paphus urbs Cypri; dedita olim, id est, iam ab antiquo tempore, ut modo diximus; amoribus, scilicet, meretriciis et impudicis; fertur, id est, dicitur; mansisse, id est, permansisse et perseuerasse; antrum, id est, lupanar et fornix; libidinis, id est, lasciuiae; sacrilegae, id est, nefariae et abominabilis; et, scilicet, fertur; coluisse, id est, honorasse tanquam deos. (fl. cvi, l. 13-16) ${ }^{10}$

Como se pode verificar, o comentador efectua três operações semânticas: recorre à sinonímia («fertur, id est, dicitur»; «libidinis, id est, lasciuiae»); serve-se da perífrase («olim, id est, iam ab antiquo tempore»); ou então fornece algumas notas esclarecedoras do sentido e do alcance das palavras do poema, frequentemente elíptico e polissémico («amoribus, scilicet meretriciis et impudicis»). Todavia, antes de passar a este esclarecimento semântico mais segmentado, torna-se, por vezes, necessário elucidar as ideias gerais presentes num conjunto de versos (sensus est...). Por exemplo, na mesma secção, Barbosa clarifica o sentido dos versos 10-14, para seguidamente explicitar o significado palavra a palavra, procedimento repetido logo depois, na análise dos quatro versos seguintes:

Culpas. Sensus est: quamuis Cypros erat peccatrix, tamen exemplo Pauli, quondam peccatoris et persecutoris ecclesiae, poterat sperare bene de diuina misericordia. Sicut enim pepercit Deus Paulo, ita et Cypriis ueniam daturum probabile erat. Paulus erat iam exemplum, scilicet, certum et antecedens; culpas, id est, peccata; posse remitti, id est, ignosci [...]. Cui nescia. Sensus est: si honestas et probitas potuit nasci praedicatione Pauli de

os objectivos que pretende atingir com esta obra didáctica: a formação das mentes e, sobretudo, a formação das almas.

10 Destacamos a negrito as palavras e expressões do poema de Arátor. 
Cypro terra tam luxuriosa, iam in terris nulla erit regio quae difficulter probitatem non capiat Pauli praedicatione [...]. Cum honestas, id est, probitas et castitas; uideatur, id est, appareat; coepisse, id est, incepisse in principio praedicationis Pauli. (fl. cvi, l. 38-54. Sublinhado nosso)

Quanto à sintaxe, Barbosa, depois de isolar os elementos da oração, fornece a ordem portuguesa ou castelhana da frase, ou seja, segue o esquema “sujeito-predicado-complementos”, a ordem sintáctica da língua-mãe dos seus discentes. Procedimento correcto, aliás, sobretudo se atendermos às dificuldades que os seus discípulos (e não só) deveriam sentir na compreensão dos versos rebuscados do autor latino. Assim, nunca Barbosa comenta os versos de Arátor seguindo a ordem das palavras no poema, constituindo esta a primeira e principal operação de âmbito sintáctico que o humanista efectua. Vejamos, por exemplo, o ordenamento vocabular de três versos de Arátor e cotejemo-lo com a disposição seguida no comentário por Aires Barbosa:

Arátor: «Hinc operum procedit apex, quia gratia maior / ad delicta uenit; culpas huic posse remitti, / exemplum iam Paulus erat». (Historia apostolica, 2, 9-11)

Barbosa: «Hinc [...] procedit [...] apex [...] operum [...], quia maior gratia uenit ad delicta [...]; Paulus erat iam exemplum [...] culpas [...] posse [...] remitti [...] huic». (fl. cvi, l. 34-42)

Nem sempre esta operação é feita de forma automática, pois, algumas vezes, o próprio comentador anuncia claramente que vai fornecer a ordem sintáctica (ordo est...) das palavras no verso, ao mesmo tempo que vai explicitando o seu sentido.

Os procedimentos semânticos implicam a permuta de palavras ou de expressões eruditas por outras mais consentâneas com os conhecimentos da língua latina por parte dos alunos. Por seu turno, a simplificação das sequências frásicas difíceis dos versos de Arátor é quase uma imposição metodológica, em função do estilo do autor e das exigências métricas da poesia. O didactismo do comentário barbosiano pode ainda ser comprovado por uma série de outros esclarecimentos, tipicamente escolares: a enunciação 
do substantivo ${ }^{11}$; a enunciação do verbo ${ }^{12}$; a explicitação do tempo, modo e voz da forma verbal ${ }^{13}$; ou ainda o constante esclarecimento da terceira pessoa do pretérito perfeito do indicativo activo, sempre que no poema aratoriano termina em - ere ${ }^{14}$.

Destacamos também o comentário estilístico pela sua singularidade, pois, apesar da frequência com que Barbosa aponta as figuras retóricas presentes no poema, raramente vai além da sua simples constatação ou de uma explicação muito sumária ${ }^{15}$.

A estes esclarecimentos, o nosso humanista acrescentava outros destaques que hoje continuariam a ser considerados normais em aulas de

11 Vd. Barbosa, op. cit., fl. cxxx, l. 36-37: «tot uasis, ablatiui casus: uasa, orum - uasis»; e fl. cxxvii, l. 30: «decoris, id est, pulchritudinis, a 'decor, oris'».

12 Vd. ibidem, fl. cxliii $\mathrm{v}^{0}$, l. 55: «Nam pastor dicitur a 'pasco, is, paui, pastum'».

${ }^{13}$ Vd. ibidem, fl. cxiiii $v^{0}$, l. 8: «et imponere, in praesenti passiuo imperatiui modi».

14 Vd. ibidem, fl. cxi v ${ }^{0}$, 1. 21-22: «uoluere, pro uoluerunt»; fl. cxiii, l. 7: «et meruere, pro meruerunt»; e fl. cxiii, l. 41: «cecinere, pro cecinerunt».

15 Vd. ibidem, fl. cix, l. 3-4: «Vt fructus uentris amoeni, id est, Christus, per periphrasin, qui est fructus uentris Virginei et semper florentis»; fl. cxiii, l. 31-32: «Iamque Paulus incedens passibus, id est, ambulans pedibus, est pleonasmus»; fl. cxiii $\mathrm{v}^{0}$, 1. 10-11: «et persona uetus, id est, claudus antiquus; progreditur, id est, ambulat; calle nouello, id est, itinere uel uia noua ipsi ueteri in infirmitate. Et est antitheton exornatio rhetorica, nam 'uetus' opponitur 'nouello'»; e fl. cxxxix, l. 2627: «O dolor, per prosopopoiian et apostrophen». Sublinhado nosso. 
Latim, como explicações de carácter métrico ${ }^{16}$, etimológico ${ }^{17}$ ou mitológico $^{18}$.

Tendo em conta que o texto de Arátor é uma epopeia bíblica, é natural que as explanações bíblicas e de carácter teológico tenham um lugar cimeiro no comentário. Sem nos querermos alargar nestas matérias, diremos, relativamente às primeiras, que Aires Barbosa procura colmatar as lacunas de Arátor, quando este omite simplemente passagens dos $\operatorname{Actos}^{19}$, além de fornecer a sua interpretação de vários passos da Sagrada Escritura. Neste âmbito, surge com particular recorrência a tipologia bíblica, ou seja, a correspodência simbólica entre o Antigo Testamento (o typos) e o Novo Testamento (o antitypos); funcionando o primeiro como uelatio do segundo, e o segundo como reuelatio do primeiro, para usarmos as palavras de Santo Agostinho (Serm. 300, 5). A exegese bíblica aparece muito bem documentada, recorrendo o comentador ao testemunho de eminentes biblistas, como S. Jerónimo e Orígenes, ou citando frequentemente as glosas bíblicas, de que se destacam os sete volumes da Biblia Latina, com explicações de

16 Um passo bem exemplificativo do comentário métrico aos versos de Arátor é o esclarecimento da aparente incongruência de Arátor quando, no verso 313 do segundo livro, usa Macedo com a sílaba do meio longa e, seis versos depois, apresenta a mesma sílaba como breve (no topónimo Macedonia): trata-se, diz Barbosa, de uma sílaba ancípite - longa em Ovídio, mas breve em Lucano -; e que no próprio grego pode excepcionalmente apresentar-se como longa; por conseguinte, os dois versos de Arátor estão metricamente correctos. Vd. Barbosa, op. cit., fl. cxvix, l. 7-10.

17 Com excepção dos nomes bíblicos, em que Aires Barbosa recorre pontualmente ao hebraico, a explicação etimológica é sempre feita com recurso ao grego.

18 Relativamente ao comentário mitológico remetemos para o excurso de Barbosa a propósito de Cupido, onde o comentador cita diversos testemunhos dos autores clássicos: Virgílio, Sérvio, Propércio, Mosco, Cícero e Ovídio. Vd. Barbosa, op. cit., fl. cvi, l. 18-32.

19 Diz Aires Barbosa, a propósito do relato bíblico no poema: «Arátor omite muitos factos que S. Lucas inseriu na história apostólica, mas o poeta, sábio e douto, só colhe as flores e deixa de lado as coisas expostas em que ele perde a esperança de poder brilhar» (fl. cxxiii, l. 35-38, tradução nossa). 
Nicolau Lira e anotações de Paulo de Santa Maria, impressa nos finais do século XV, e amplamente difundida ${ }^{20}$.

A principal matéria de ordem teológica que o texto de Arátor explora é a questão do baptismo ${ }^{21}$. Aires Barbosa dedica várias páginas quer à interpretação das passagens que se relacionam com o baptismo, quer às heresias que surgiram a este propósito. Por exemplo, no comentário aos versos 577-600 do segundo livro da Historia apostolica, rebate longamente a repetibilidade do baptismo, postulada pelos Donatistas, fundamentando-se sobretudo em Santo Agostinho, cujos escritos anti-donatistas cita exaustivamente ${ }^{22}$.

Em rigor, as explanações bíblico-teológica não ocupam sempre o mesmo espaço e destaque ao longo do comentário barbosiano, mas a metodologia adoptada pelo humanista ao longo das secções em que o texto está dividido é constante. E, por esta razão, não há uniformidade na dimensão do comentário às seç̧ões, embora elas contenham aproximadamente o mesmo número de versos comentados. O humanista começa quase sempre pela contextualização dos quadros bíblicos apresentados por Arátor, a que se segue o esclarecimento da sintaxe e do significado das palavras, expressões ou frases, divagando depois para considerações de ordem teológica, estilística, métrica, entre outras.

Mas, além destas explicações, expectáveis numa cadeira de Gramática e na análise de um texto de pendor religioso, o professor de latim aduz inúmeras outras que hoje talvez fossem consideradas divagações extravagantes, como os passos em que são dadas verdadeiras lições de geografia, de astronomia, de biologia ou de arqueologia ${ }^{23}$, entre outros

20 A edição impressa mais antiga de que temos conhecimento é a seguinte: Biblia Latina, cum postillis Nicolai de Lyra et expositionibus Guillelmi Britonis in prologos S. Hieronymi et additionibus Pauli Burgensis replicisque Mathiae Doering, Venetiis, impens. Octaviani Scoti, 1489. Na Biblioteca Geral da Universidade de Coimbra existe um exemplar, publicado na cidade de Lião, em 1545.

21 As considerações aratorianas acerca do baptismo são mesmo consideradas por alguns estudiosos a trave mestra do seu poema. Cf. Richard Hillier, Arator On the Acts of the apostles: a baptismal commentary, Oxford, Clarendon Press, 1993, passim.

22 Vd. Barbosa, op. cit., fl. cxxviii e cxxviii vo .

23 Para exemplificarmos sumariamente cada um destes pontos, remetemos para os seguintes passos: fl. cvi, l. 7-13, onde Barbosa se refere à geografia de Salamina, 
assuntos de pendor menos gramatical ou teológico. Ora, devemos relacionar este facto com a época renascentista e com aquilo que um professor e um aluno da época esperavam, respectivamente, ensinar e aprender numa aula de Latim: as pessoas queriam-se sábias, e isso implicava não apenas um aprofundamento da matéria mais específica, mais especializada, mas também uma visão global de tudo o que diz respeito ao Homem, ou seja, o sentido etimológico de humanidades, que está também na raíz da palavra «humanismo». Um aluno de Latim não se importava com esses excursos; pelo contrário, exigia-os, pois que lhe aumentavam o que hoje designamos por cultura geral. E, neste aspecto, o comentário barbosiano é pedagogicamente válido para os dias de hoje, constituindo uma chamada de alerta para o erro das excessivas especializações que ignoram depois tudo o resto, mesmo que esse "resto" seja uma matéria adjacente à especialidade, formando alunos óptimos, por exemplo, em Medicina, em Linguística ou em História, mas depois ignorantes quanto ao mais. Esse amor por um saber que diz directamente respeito ao Homem é o sentido mais profundo do humanismo de Aires Barbosa e daquilo que nós, professores de Letras, fazemos na nossa actividade lectiva e académica, isto é, somos amantes da sabedoria («filósofos») e temos, além disso, o desejo e o prazer de comunicar esse saber («filólogos»). Em suma, o espírito que subjaz aos métodos de Aires Barbosa, ainda que com quinhentos anos, pode curiosamente, por este prisma, ser considerado moderno.

A prova de que Aires Barbosa era um modelo de filólogo está, porventura, no facto de os alunos lhe terem pedido para publicar os seus comentários das aulas, revelando assim o interesse (e, quem sabe, o entusiasmo) despertado pelo professor. Não se sabe, mas é possível especular, até que ponto os atritos levantados entre colegas pelos métodos de Aires Barbosa não se deveriam também à inveja destes últimos, acicatada pela adesão dos discentes às aulas do nosso humanista e pelo notável saber

citando Estrabão, Horácio e Justino; fl. cxliii e cxliii v ${ }^{0}$, em que o humanista faz um longo excurso sobre astronomia, a propósito da explicação do calendário judaico e grego, justificando a sua prolixidade nesta matéria com o esclarecimento da divulgadíssima expressão de Suetónio Ad calendas Graecas; fl. cxlv, 1. 2-16, onde o comentador se refere às propriedades do veneno viperino, atestado por autores como Virgílio, Plínio-o-Velho ou Pedro Aponense; fl. cxxxiii, l. 20-50, em que Barbosa se debruça sobre o passado arqueológico de Tróia, estendendo também o seu comentário ao cotejo entre a Tróia homérica e a paulina. 
deste. No comentário ao segundo livro, Barbosa integra, aliás, uma asserção dirigida a ele próprio, e que configura aquilo que poderíamos designar como "conversa de corredor" entre mestres da instituição salmantina:

E assim também um pretenso sábio da língua latina negava categoricamente que se pudesse encontrar o substantivo nepos nos autores consagrados, a não ser com a significação habitual. Dizia-me, pois: «Ó Aires, por certo que jamais nepos poderá significar o filho do irmão na obra daqueles antigos». ${ }^{24}$

Respondeu o humanista ao incógnito filobárbaro que bastaria ler um passo de Ovídio para melhorar os seus conhecimentos de língua latina ${ }^{25}$. Este passo dá-nos uma pequena ideia da conflitualidade latente que existia entre Aires Barbosa e outros colegas igualmente habilitados para ministrar a cátedra de Gramática, em Salamanca. Com efeito, é relativamente fácil compreender que a excelência de Aires Barbosa, um estrangeiro, não o esqueçamos, em terras salmantinas, tenha despertado sentimentos menos nobres naqueles.

De facto, o humanista aveirense leccionou grego a partir de 1485, conseguiu a cátedra de Retórica em 1503 e, por fim, dado o maior prestígio e vencimento da disciplina de Gramática, concorreu a esta última cátedra por três vezes. Da primeira vez, em 1503, foi vencido por Pedro Espinosa, num concurso recheado de polémica e comprovativo de que «nem sempre venciam os melhores» ${ }^{26}$. Depois, aquando da morte deste em 1505, Barbosa desistiu

24 Vd. José Henrique Manso, Comentário de Aires Barbosa ao segundo livro da "Historia apostolica" de Arátor: estudo filológico, fixação do texto, tradução e notas, tese de Doutoramento apresentada à Universidade da Beira Interior, 2009, p. 73-74.

25 Os versos ovidianos são os seguintes: «Sic regat imperium terrasque coerceat omnes / Caesar, ab Aenea qui tibi fratre nepos» (Ov., Pont., 3, 3, 61-62). Na verdade, a lição mais comum é «qui tibi fratre tuus». Todavia, algumas edições mais antigas registam a variante apresentada pelo humanista, por exemplo: P. Ouidii Nasonis quae supersunt, ad optimorum librorum fidem accurate edita, curauit Antonius Richter, Lipsiae, sumptibus et typis Caroli Tauchnitii, 1828, p. 577.

26 Vd. Américo da Costa Ramalho, Para a história do Humanismo em Portugal, I, Coimbra, INIC - Centro de Estudos Clássicos e Humanísticos da Universidade de Coimbra, 1988, p. 57. Costa Ramalho vê nesta derrota do humanista um caso exemplificativo de como, por vezes, candidatos menos competentes 
em favor do outro concorrente, o seu amigo e antigo mestre António de Nebrija; e só em 1509, por renúncia de Nebrija, Aires Barbosa conseguiu a tão almejada cátedra. Deixou vacante a Retórica, mas continuaria a reger a catedrilha de Grego. A excelência do seu ensino em Gramática seria comprovada pela publicação dos seus opúsculos didácticos neste domínio, pela edição da sua obra maior, o comentário à Historia apostolica ${ }^{27}$, e ainda pelo facto de a cátedra de Gramática continuar a ser propriedade de Aires Barbosa, mesmo após a sua aposentação, até à sua morte em 1540, ano em que foi nomeado o novo catedrático, António de Aguillar.

Em suma, às duas curtas missivas de Arátor que antecedem a Historia apostolica e aos 2.326 versos que compõem esta epopeia bíblica dedicou o humanista português Aires Barbosa uma obra composta por centena e meia de fólios compactos. Raro é o passo de Arátor que não mereça uma observação por parte do comentador e, frequentemente, são até várias as leituras propostas. Com certeza que o seu carácter pedagógico retira alguma erudição ao comentário, mas, por outro lado, esta obra fornece-nos um magnífico testemunho do ensino do latim e da literatura latina ao tempo do nosso humanista.

JOSÉ HENRIQUE RODRIGUES MANSO

conseguiam cátedras corrompendo os estudantes para conseguirem o seu voto, e sublinha que à derrota também não terá sido alheio o facto de Aires Barbosa ser português: «Aires Barbosa apresentou-se a concurso com um outro candidato que de modo algum podia comparar-se-lhe. Era, porém, Pedro de Espinosa, o rival, castelhano e mais jovem. O prestigioso "Mestre Grego", como lhe chamavam, foi batido» (ibidem, p. 59).

27 Entre 1511 e 1517, o humanista fez sair a lume, sempre em Salamanca, cinco obras de carácter didáctico, destinadas, fundamentalmente, a esclarecer os seus discípulos acerca das matérias leccionadas: em 1511, a Relecção sobre os verbos oblíquos, onde analisa a questão dos verbos ditos impessoais; em 1515, um tratado sobre métrica latina, designado pelo neologismo Epometria; em 1516, o Comentário à "Historia apostolica” de Arátor; e, em 1517, uma publicação conjunta de dois opúsculos que versam sobre a pronúncia e grafia correctas da língua latina, intitulados De Prosodia e De Ortographia, respectivamente. 